\title{
ARTIGOS
}

\section{CORPOS EM MOVIMENTO NO ESPAÇO: NARRATIVAS ESCOLARES}

ALEXANDRA LEANDRO

\section{RESUMO}

O modo como as mobilidades e performances espaciais dos alunos são disciplinadas pelos diferentes educadores que habitam a escola permite-nos refletir sobre a relevância do espaço corporeamente produzido na configuração da experiência escolar. Em cada ano, múltiplas fronteiras espaciais são atualizadas em busca de um renovado equilíbrio entre abertura e fechamento, distância e proximidade, com vista à defesa e (re)construção do território dos adultos. A forma como o espaço escolar é distribuído e investido de sentido é um processo incerto e conflituoso, sendo que, no contexto do funcionamento diário de uma escola, a reflexão em torno dessa dimensão territorial leva-nos a olhar para a mobilidade e ocupação espaciais como importantes recursos individuais, grupais e institucionais.

ESCOLAS • CORPO • ESPAÇO • DISCIPLINA

\section{BODIES IN MOVEMENT IN SPACE: SCHOOL NARRATIVES}

\section{ABSTRACT}

The way in which student's spatial mobility and performance are disciplined by the different educators in the schools allow us to reflect on the relevance of bodily space produced in the school experience. Each year, multiple spatial boundaries are updated in search of a new balance between opening and closing, distance and proximity, in order to protect and (re)construct adult's territory. The way school space is distributed and invested with meaning is an uncertain and contentious process. In the daily operation of a school, the reflection on this territorial dimension leads us to regard spatial mobility and occupation as important individual, group and institutional resources. 
La manière par laquelle les mobilités et les performances spatiales des élèves sont disciplinées par les différents éducateurs à l'école nous permettent de réfléchir sur l'importance de l'espace corporel produit dans la configuration de l'expérience scolaire. Chaque année, des multiples frontières spatiales sont actualisées à la recherche d'un équilibre renouvelé entre l'ouverture et la fermeture, la distance et la proximité en vue de garantir e reconstruire le territoire des adultes. La forme par laquelle l'espace scolaire est distribué et investi de sens est un processus incertain et conflictuel. Ainsi, dans le contexte du fonctionnement quotidien d'une école, la réflexion au sujet de cette dimension territoriale nous mène à regarder la mobilité et l'occupation spatiales comme d'importantes ressources individuelles, groupales et institutionnelles.

ÉCOLES • CORPS • ESPACE • DISCIPLINE

\section{CUERPOS EN MOVIMIENTO EN EL ESPACIO: NARRATIVAS ESCOLARES \\ RESUMEN}

El modo en el que las movilidades y desempeños espaciales de los alumnos son disciplinados por los diferentes educadores en la escuela nos permite reflexionar sobre la relevancia del espacio corpóreamente producido en la configuración de la experiencia escolar. Cada año, múltiples fronteras espaciales son actualizadas en búsqueda de un renovado equilibrio entre apertura y cierre, distancia $y$ proximidad, con miras a la defensa y (re)construcción del territorio de los adultos. La forma en la que el espacio escolar se distribuye y adquiere sentido es un proceso incierto y conflictivo; en el contexto del funcionamiento diario de una escuela, la reflexión en torno a esta dimensión territorial nos lleva a mirar hacia la movilidad y la ocupación espaciales como importantes recursos individuales, grupales e institucionales. 
Enquanto estou sentada no átrio, vejo um grupo de alunos fazer umas das travessias mais improváveis: abeirados na porta que separa a zona do gabinete do átrio, olham em volta, procurando perceber se existe alguém que os possa impedir. Este é um momento raro, em que nenhum adulto, para além de mim, se encontra no átrio, e em que o interdito se torna possivel. Vão atravessando a zona, primeiro lentos, silenciosos e expectantes; depois, aceleram um pouco, por forma a encurtar o tempo de travessia. Os seus corpos vão contraídos, encurvados, como se procurassem uma certa invisibilidade. Finalmente, conseguem atravessar o PBX e aceder à porta principal do edifício, que Ihes dá passagem para o exterior. (LEANDRO, 2013, p. 141)

O CONTEXTO DE UMA ETNOGRAFIA DESENVOLVIDA EM TORNO DAS QUESTÕES DE (in)segurança nas escolas portuguesas, ${ }^{1}$ parti para o campo com a consciência da complexidade do tema escolhido, e da necessidade de trabalhar a indisciplina discente como um objeto multifacetado, que se ia configurando, ao longo da pesquisa, com base nas experiências concretas dos sujeitos e das instituições quotidianamente experimentados e reinventados.

A maximização dos espaços de observação permitiu evitar uma seleção apriorística dos dados a recolher, potenciando o questionamento em torno do modo como a experiência escolar envolve a articulação e o confronto entre distintas racionalidades e modos de atuar. Optou-se, desse modo, por uma definição concreta de indisciplina (AQUINO, 2011, p. 468), capaz de enquadrar os comportamentos dos alunos suscetíveis de serem entendidos como uma violação às regras estabelecidas, bem como os processos de censura e de intervenção sobre aqueles comportamentos desenvolvidos pela administração escolar e pelos diferentes profissionais da escola. Privilegiou-se o tratamento da indisciplina en-

O trabalho de campo teve lugar em Portugal entre 2008 e 2012, em diferentes estabelecimentos de ensino, envolvendo os diferentes ciclos do Ensino Obrigatório, e culminou na realização e discussão de uma tese de doutoramento (LEANDRO, 2013) quanto processo de construção institucional, procurando-se desvendar até que ponto os processos de disciplinação dos alunos envolviam a recomposição e reinvenção de distintas configurações de poder.

À medida que a pesquisa avançava, foi-se tornando incontornável que uma parte significativa dos comportamentos dissonantes dos discentes, sobre os quais recaía a preocupação de corrigir e reorientar, 
prendia-se com as mobilidades daqueles dentro do edifício escolar e com as dinâmicas interpessoais e grupais que evoluíam a partir do modo como o espaço estava distribuído.

O progressivo recolher dos dados de campo ia apontando para a necessidade de compreender o modo como o espaço físico da escola era simbolicamente investido pelos diferentes sujeitos, e como as fronteiras associadas à sua distribuição e utilização iam sendo reforçadas, reinventadas e contestadas, numa base quotidiana.

A reflexão em torno das estratégias organizacionais destinadas à regulação da mobilidade espacial, assim como a observação das performances espaciais, permitiam equacionar este mundo como um lugar de diferentes possibilidades de produção institucional, numa complexa mistura entre proximidade e distanciamento.

As observações realizadas, ao longo de dois anos letivos, no átrio de uma das escolas que constituiu locus e objeto da etnografia revelaram-se particularmente significativas para compreender a importância que a distribuição dos diferentes espaços ${ }^{2}$ e as fronteiras internas que se vão configurando têm para a inscrição e experimentação dos diferentes estatutos.

Tendo em conta uma matriz específica de poder, os alunos funcionam como habitantes transitórios em relação aos quais o espaço escolar vai sendo concedido e/ou limitado, a partir de um determinado ordenamento físico, pedagógico e moral. Paradoxalmente, ou talvez não, os alunos funcionam, ao mesmo tempo, como a matéria-prima que dá sentido ao trabalho pedagógico e as margens porosas de uma instituição central e estruturante, que se vai fazendo, desfazendo e refazendo com base no reforço contingente - e, em certa medida, sinuoso - dos dispositivos de controlo. No processo de rotinização desse controlo, os alunos aprendem quão distantes se encontram das decisões concernentes à distribuição dos recursos na escola.

A defesa de certos espaços que configuram o que poderíamos denominar o território exclusivo dos funcionários da escola envolve o problemático esforço de construção e manutenção de limites e fronteiras; uma trama complexa e dinâmica, que se vai perpetuando e renovando, ano após ano, tecida a partir das diferentes possibilidades de desconstrução e reconstrução dos interditos e das possibilidades.

O campo disciplinar é produzido pelos diferentes sujeitos que habitam a escola, tendo em conta um certo campo de possibilidades, e, nesse sentido, a regulação das mobilidades discentes e as estratégias de resistência e afrontamento ativadas pelos alunos, na dupla dimensão individual e grupal, limitam-se e invertem-se mutuamente, concedendo às relações de poder um caráter contínuo e transformável (FOUCAULT, 1994a).

Os educadores testam, numa base quotidiana, o tenso e difícil projeto pedagógico de internalização, pelos alunos, das normas tidas 2 Essa escola constituía a sede de um agrupamento escolar - uma configuração que agrega, numa mesma unidade organizacional, estabelecimentos de ensino que vão do pré-escolar ao $3^{\circ}$ ciclo do Ensino Obrigatório -, e incluía os 2 은 e 3 ciclos do ensino, a que correspondem os 5-9anos de escolaridade. 
como indispensáveis à defesa e manutenção de uma certa ordem socioespacial. Esse é, sem dúvida alguma, um trabalho continuado e permanentemente desafiado. Na verdade, e apesar de todo o investimento, era sempre possível observar alunos que tentavam contornar os limites, experimentando outros mapeamentos possíveis, a exigir a reforçada atualização do controlo exterior.

Por sua vez, os interditos relacionados com as passagens por certos locais da escola, embora constituíssem fonte de frustração para os alunos, comunicando-lhes a sua posição de subordinação, funcionavam também como estímulos à recreação lúdica do quotidiano escolar, e, nesse sentido, como matéria-prima para o continuado problematizar da escola enquanto espaço de socialização.

Longe de poder assumir a instituição escolar como um ordenamento mecanicamente ajustado a uma finalidade global, as interações e os questionamentos desenvolvidos ao longo da pesquisa mostraram quão importante é olhar para lá da legibilidade aparente da organização escolar, procurando perscrutá-la enquanto lugar do político, quotidianamente reconstruído a partir dos processos de contestação e negociação do poder (ABÉLÈS, 1995).

\section{ESPAÇO, CORPO E SOCIABILIDADES - A PROTEÇÃO DO "PARAÍSO"}

A construção da escola como espaço habitável (RESENDE, 2008) envolve múltiplos modos de apropriação e regulação do espaço, do corpo e das sociabilidades. As observações etnograficamente produzidas em torno do quotidiano escolar apontaram, desde cedo, para a importância da mobilidade e ocupação espacial enquanto recursos individuais e grupais, úteis à afirmação institucional dos diferentes intervenientes.

Os responsáveis pela administração da escola assumiam a regudestinado ao lazer de alunos e professores nos intervalos das aulas. função vigiar o interior e a entrada da escola eram geralmente policiais e militares aposentados. Os auxiliares tinham como funções a limpeza e manutenção do edifício escolar, o controlo das entradas e saídas da escola na portaria, a gestão do acesso ao PBX, à papelaria e reprografia, e a vigilância dos alunos em diferentes espaços-tempos da escola. Esses dois grupos funcionais trabalhavam em estreita interligação. lação espacial como um importante campo de ação, controlando a mobilidade dos alunos através da definição de todo um conjunto de espaços interditos e percursos obrigatórios.

Os intervalos, ou recreios, ${ }^{3}$ funcionaram a esse nível como uma unidade de observação especialmente importante para compreender o modo como os alunos se apropriavam de espaços que lhes estavam temporariamente cedidos, e relativamente aos quais os mesmos impunham utilizações renovadas, que contrastavam frequentemente com as interpretações impostas pelos funcionários das escolas.

Os intervalos eram, então, momentos em que a presença de vigilantes e auxiliares se fazia sentir com maior evidência, ${ }^{4}$ mostrando que as dinâmicas recreativas dos alunos eram entendidas e experimentadas pelas estruturas de controlo da escola como espaços de desordem potencial, eminente e efetiva. O olhar disciplinar relativamente a esses 
espaços-tempos oscilava entre a sua importância para a socialização interpares e para a revitalização das energias e as dificuldades de contenção de um espaço arredio, onde podiam ocorrer comportamentos turbulentos. Os critérios de ordem desenvolvidos pelos profissionais da escola problematizavam, desse modo, esses espaços-tempos recreativos como lugares criativos e transformáveis (DELALANDE, 2005), reorientando e, não raras vezes, refreando a plasticidade lúdica própria das dinâmicas discentes.

A pesquisa histórica em torno da ecola indica-nos que o disciplinamento dos corpos dos alunos em movimento no espaço escolar faz parte de um trabalho de aculturação, que tem atravessado gerações, e que funciona por meio de um complexo processo de inculcação de normas, valores e representações de ordem específicos (JULIA, 2001). Esse trabalho é, naturalmente, um terreno propício à produção de fronteiras simbólicas, funcionando a vigilância escolar como processo de mapeamento moral. O mapa que daqui resulta é produzido no cruzamento entre as normas formais e escritas e os instrumentos pedagógicos - materiais e comunicacionais -, que vão sendo produzidos, reproduzidos e (re)inventados nos quotidianos escolares.

A exploração de um dos exemplos etnográficos desenvolvidos ao longo dessa experiência de investigação permitiu compreender melhor as implicações dessa geografia moral. Numa das escolas-sede onde teve lugar a etnografia, ${ }^{5}$ era possível ver as palavras purgatório e inferno no monitor das câmaras de videovigilância, a assinalar os espaços por onde os alunos circulavam, em massa, durante os intervalos. Esse era um enigma que importava decifrar, percorrendo a natureza e sentido dos significados encobertos, e abrindo para todo um campo de descoberta, inesperado, indisciplinado e, a médio prazo, esclarecedor (PAIS, 2002). Tal como eu teria oportunidade de desvelar ao longo do trabalho de campo, os termos purgatório e inferno simbolizavam a agitação quotidiana produzida pelos corpos dos alunos, em movimento e em interação, e o investimento material e simbólico quotidianamente experimentado pelos funcionários da escola, com vista a vigiar e a regular essas dinâmicas discentes.

A concentração dos alunos no interior do edifício constituía, no contexto dessa escola, um aspeto particularmente problemático. Era frequente os diferentes profissionais queixarem-se do facto de os alunos não utilizarem de modo suficiente o espaço exterior, mesmo nos dias em que não chovia, fazendo dos corredores espaços preferenciais para o desenvolvimento das suas brincadeiras. Era visível o desconforto experimentado pelos adultos relativamente a uma certa paisagem escolar desenhada pelas dinâmicas ruidosas e espacialmente expansivas dos alunos, que corriam, em grande velocidade, ao longo dos corredores para se apanharem ou fugirem uns dos outros. Impedir o acesso dos alunos 
aos espaços diretivos e administrativos, bem como à sala de professores, constituía, nesse sentido, um aspeto fundamental do reforço dos perímetros de segurança que permitiam delimitar e defender alguns locais da escola, considerados território exclusivo dos respetivos funcionários. O facto da escola em análise ser constituída por um edifício único tornava essa tarefa defensiva um desafio permanente.

Um dos locais mais importantes para a observação dessa difícil e tensa coabitação era um átrio central que ficava no seguimento da porta principal do edifício escolar e que permitia a passagem para uma grande variedade de espaços interditos, nos quais alunos e seus familiares só podiam circular com autorização expressa. A proteção desse local envolvia um complexo processo institucional através do qual os perímetros de segurança iam sendo continuamente ativados, contestados e reforçados.

A porta principal do edifício alertava-nos, desde logo, para a existência de um acesso condicionado: estava frequentemente fechada, com o apoio de uma mola, e a luz a incidir nos vidros dificultava o olhar para o interior. O átrio que era guardado com tanto empenho ficava no seguimento dessa porta e de uma espécie de antecâmara onde se situava o PBX, ${ }^{6}$ que era vigiado por uma auxiliar, cujo local de trabalho era composto por uma mesa e uma cadeira. Entrados no átrio, podíamos visualizar os serviços administrativos e a porta que dava para a sala de professores. Na continuação desses lugares, separadas por umas portas envidraçadas, ficavam a sala da Direção e outras divisões destinadas às diferentes atividades a realizar pelos professores, nomeadamente preparação das aulas e atendimento dos familiares dos alunos. Do lado oposto do átrio, um segundo conjunto de portas que permitia o acesso a outros serviços, entre os quais a ludoteca e um gabinete de apoio aos alunos. Um terceiro conjunto de portas separava o átrio de um corredor - o "Purgatório" - que, por sua vez, permitia a passagem para um segundo átrio - o "Inferno" -, para onde todos os alunos desembocavam nos intervalos, vindos das salas de aulas.

Ao contrário dos professores e restantes funcionários, os alunos tinham obrigatoriamente de entrar para as aulas pelas portas laterais do edifício. Para além dessa entrada obrigatória, a sua passagem pelo átrio central da escola constituía quase sempre um interdito, à exceção das situações em que necessitavam de contactar com os serviços administrativos, a Direção ou algum/a professor/a, sendo que, nessas ocasiões, a sua presença tinha de ser devidamente justificada e orientada.

Existia, contudo, um momento extraordinário em que a entrada dos alunos no átrio da escola era experimentada com relativa abertura: uma visita realizada à escola-sede do agrupamento no terceiro e último período do ano letivo - entre maio e junho -, e que visava a preparar os alunos do último ano do $1^{\circ}$ ciclo $^{7}$ para a transição que implicava a sua passagem para o primeiro ano do $2^{\circ}$ ciclo. ${ }^{8}$ Essa transição era entendida 
pelos profissionais das diferentes escolas como potencialmente problemática, não apenas do ponto de vista da aquisição de conhecimentos, mas também tendo em conta a adaptação dos alunos às regras que envolviam as sociabilidades e a gestão do espaço na escola que os iria integrar. Tal como foi possível perceber na comparação entre diferentes pesquisas e escolas, a transição entre ciclos de ensino e entre estabelecimentos escolares configura um momento de intensa problematização dos processos de maturação institucional dos alunos, envolvendo essa passagem a procura de ajustamento a um vasto conjunto de expectativas comportamentais (ABRANTES, 2008).

Os professores que guiavam essas visitas eram categóricos no modo como assinalavam os interditos espaciais, denominando os lugares a defender como "espaços reservados aos adultos". No contexto dessas visitas à escola-sede, a passagem pela Sala dos Professores era sempre cuidadosamente preparada, no sentido de ser o mais breve e discreta possível. Antes de atravessar o limiar da porta, cuidadosamente encerrada com uma mola, o professor-guia fazia uma paragem de alguns minutos para explicar a necessidade dos alunos evitarem esse lugar, nomeadamente para procurar algum/a docente, orientando-os para pedirem ajuda a uma auxiliar. Por sua vez, a Sala da Direção, que ficava mais recuada, num lugar particularmente defendido dos olhares e das eventuais tentativas de aproximação, constituía local incontornável da visita, para que os membros diretivos se apresentassem e dessem as boas vindas aos alunos. Essa abertura era, no entanto, desde logo, relativizada, sendo esse local apresentado como um lugar de disciplinação por excelência, para onde eram levados os alunos que não se portavam bem.

Depois desse breve período de iniciação, e ao longo da sua prolongada experiência de escolarização, a gestão da circulação dos alunos por aqueles locais era reforçada pela utilização de certos recursos cénicos, dos quais se destacavam, pela sua centralidade visual, a sinalética colocada nos vidros das portas, com termos a assinalar a passagem proibida - "Alunos: Proibida a Entrada" -, frequentemente secundados pelo emprego do sinal de trânsito indicador de sentido proibido. ${ }^{9} \mathrm{O}$ corpo e os dizeres dos funcionários funcionavam, igualmente, como instrumentos fundamentais na contínua criação e recriação de obrigações e proibições, na tentativa de impedir que os alunos atravessassem os espaços proibidos ou aí permanecessem. A força performativa das palavras de interdição proferidas pelos funcionários contracenava com a perseverança com que os alunos ensaiavam e, por vezes, realizavam essas passagens proibidas.

De facto, embora exercida de um modo continuado e organizado, a vigilância não era nem omnipotente nem omnipresente, envolvendo momentos de intermitência que possibilitavam a transgressão das regras e a problematização da autoridade. Esse era um jogo em que

Foi possivel encontrar esse tipo de sinalética em outras escolas do ensino básico e do ensino secundário. 
os alunos aprendiam o caráter contornável dos interditos e experimentavam, alguns com particular entusiasmo, o potencial lúdico associado ao reescrever das fronteiras. Essa era uma competição que se ia enunciando quotidianamente, em diferentes momentos, e que envolvia diferentes coreografias: algumas em evidente confronto com as normas escolares e com os funcionários que as tentavam fazer respeitar; outras em configurações mais discretas, procurando uma certa invisibilidade, capaz de evitar recriminações.

No segundo ano letivo da pesquisa, a integração de novos membros nos corpos diretivos trouxe um renovado controlo dos trajetos a impor aos alunos na passagem das salas de aula para o recreio, durante os intervalos. A partir de um trabalho conjunto entre membros da direção - uma subdiretora e duas adjuntas - e várias auxiliares, os alunos eram orientados desde que saíam das salas de aula até aos corredores centrais do piso térreo da escola, onde era permitido estarem durante o recreio.

Através dessa proximidade física, os membros da direção aproveitavam os seus corpos e o seu estatuto institucional para orientar os movimentos dos alunos, na produção de um mapa o mais explícito possível. Algumas semanas depois do início do ano letivo, os membros da direção já se tinham retirado desse acompanhamento direto, estando as auxiliares responsáveis por fazer cumprir, numa base quotidiana, as trajetórias, desse modo, normativamente linearizadas. Esse controlo exigia um verdadeiro trabalho de equipa: no piso superior, em cada conjunto de escadas, permaneciam, no seu posto, duas auxiliares, com a função de obrigar os alunos a descerem para o piso térreo até ao "inferno", evitando, desse modo, que aqueles permanecessem no piso superior ou tentassem utilizar as escadas que permitiam aceder à zona da direção e às salas de trabalho dos professores. Depois desse primeiro objetivo estar cumprido, uma dessas funcionárias permanecia no piso superior e a colega descia para ajudar no controlo dos corredores.

Embora significativamente eficaz, essa gramática espacial não impedia em absoluto as derivações que iam sendo introduzidas pelos educandos, na tentativa de experimentar o espaço como uma capacidade (JIMÉNEZ, 2003). Ao expandir as possibilidades de circulação, os alunos vivenciavam o seu corpo como uma força sensível e simbólica (GALLO; MARTINEZ, 2015, p. 616), capaz de produzir sentido e de contradizer a racionalidade dominante. Uma gramática que escapava, enquanto tal, aos olhares disciplinadores dos docentes e restantes funcionários escolares, mas que se apresentava em toda a sua efetividade ao perscrutar da investigadora.

Para além desses processos de relativização, desenhados e impostos pelos alunos, algumas soluções, encontradas num determinado espectro de possibilidades, envolviam claramente um caráter contingente, 
concorrendo, mais uma vez, para questionar uma certa imagem da escola enquanto estrutura burocrática, perfeitamente ordenada nas suas modalidades organizacionais e eficaz nos seus efeitos (NUGENT, 2004).

Durante o segundo ano letivo da pesquisa, o reforço dos perímetros de segurança do átrio central da escola implicou também o fechamento à chave do conjunto de portas que separava esse lugar da zona da ludoteca e do gabinete de apoio, serviços que estavam especialmente destinados aos alunos. Era esperado, e tudo era feito nesse sentido, que os alunos acedessem a esses serviços através das escadas que vinham do segundo piso, onde tinha lugar a maioria dos tempos letivos, evitando, desse modo, a passagem através das portas envidraçadas. Essa fronteira envolvia, porém, uma especial vulnerabilidade, tendo em conta que, para os alunos, a passagem pelo átrio central encurtava de modo evidente o acesso aos seus espaços de recreação, tornando-se especialmente apetecida e tentada. Em reação a essas investidas discentes, a porta mantinha-se, então, fechada à chave, e as chaves iam sendo distribuídas aos profissionais da escola à medida das necessidades de funcionamento das atividades. A passagem para um novo ano letivo trouxe, contudo, novidades. Tendo em conta que o espaço dentro da escola é um recurso escasso, foi necessário retroceder nessa solução, já que a zona da ludoteca tinha duas salas de aula que começaram a funcionar em permanência, tornando, desse modo, menos prático o fechamento à chave da porta. A defesa do átrio central ficou, então, de novo, a depender quase exclusivamente da vigilância das auxiliares.

Esse olhar que se prolonga pelas diferentes temporalidades desses processos permite devolver ao quotidiano escolar a sua historicidade (PAIS, 2002) e tomar as vivências que têm lugar na escola como elementos fundamentais da construção de distintos presentes, que se inscrevem numa memória coletiva e num futuro marcado por salientes estruturas e modalidades de socialização e de construção de sentido.

\section{CURRÍCULO NORMATIVO E NARRATIVAS CORPORAIS}

Equacionar os corpos, em interação e em movimento, nos múltiplos espaços pedagógicos que compõem o quotidiano escolar, implica abraçar “o desafio de nos percebermos como seres corporais" (NÓBREGA, 2005, p. 610) e de procurar identificar e compreender uma certa geografia do corpo (p. 612), produzida no cruzamento entre necessidades, desejos e normas; entre os dispositivos normativos e coreografias que expandem o edifício escolar em diferentes e renovadas configurações.

Os modos de regulação dos corpos dos discentes, sobre os quais temos vindo a refletir, fazem parte de um currículo normativo abrangente, que inclui aspetos transversais do modo como os processos de escolarização vão sendo organizados, associados à ideia de imobilidade 
corporal como elemento estruturante e estruturador das aprendizagens (RATTO, 2007, p. 492).

A deslocação dos corpos dos alunos, no espaço e no tempo, envolve todo um conjunto de expectativas normativas associadas à velocidade, à direção e ao nível de ruído, fixadas nos documentos reguladores da escola, e ciclicamente transmitidas e experimentadas em cada ano letivo. A consulta conjunta e comparada dos regulamentos internos de diferentes escolas permitiu a identificação de um roteiro prescritivo coincidente, ${ }^{10}$ destinado a regular a deslocação para as salas de aulas, a permanência nesses espaços e a posterior saída para os intervalos.

A entrada e saída dos alunos das salas de aula deve obedecer a movimentos corporais ordeiros, contidos e ordenados, com o menor nível de ruído possível; espera-se que os educandos não gritem, não corram e não se empurrem uns aos outros, por forma a não perturbarem o bom funcionamento das atividades escolares.

Essas normas envolvem a tentativa de organização dessas transições, a boa passagem dos espaços e tempos recreativos dos alunos para os espaços e momentos letivos, através da redução, ao mínimo, do potencial de desordem que está associado a esses momentos intersticiais.

Na fábrica de corpos, que é a escola, a conformação do corpo baseia-se nas, ainda prevalecentes, equivalências entre "não movimento" e "bom comportamento" (STRAZZACAPPA, 2001), e entre bom comportamento e não ruído.

O âmago da escola, enquanto instituição e organização, é o espaço-tempo aula, onde os alunos recebem os conteúdos curriculares transmitidos pelos professores, com vista à sua qualificação certificada e a um futuro encaixe socioprofissional. Manter os alunos focados nesse processo revela-se frequentemente uma tarefa complexa, a exigir um esforço acrescido de regulação dos outros espaços-tempos. Trata-se de uma específica doxa escolar que faz depender de uma "ordenação estrita das condutas” a eficácia do trabalho escolar (AQUINO, 2011, p. 462).

O modo como as movimentações dos alunos são reguladas participa, assim, de todo um aparato pedagógico, que expande o currículo escolar, e faz parte dos processos de transmissão cultural presentes na escola. A dimensão prescritiva da regulação do corpo no espaço envolve toda uma adaptação a certos princípios mecânicos, moralmente investidos, e que implicam escolhas sociais e institucionais (MAUSS, 1983). Esse modo específico de configurar o processo educativo dentro das escolas constitui um projeto de longa duração, no qual e a partir do qual as instituições escolares foram assumindo um lugar central na construção de uma economia do corpo, associada à procura de eliminação dos excessos, concebidos enquanto desperdício (CRESPO, 1990). Esse paradigma, embora doseado por outras noções da infância e de maturação social, continua muito presente nas escolas, enquadrando alguns dos 
mecanismos de regulação dos comportamentos e das aprendizagens formais e informais.

Enquanto parte integrante de um vasto conjunto de experiências formadoras que têm lugar na escola, esse currículo normativo, quer na sua dimensão explícita e codificada quer na sua dimensão quotidianamente experimentada, prende-se com dimensões incontornáveis das práticas e processos pedagógicos que se cruzam na escola - a necessidade de coabitação entre diferentes sujeitos, estatutos e expectativas, e a demanda de adaptar as gerações mais jovens a um amplo projeto de integração moral e social (PERRENOUD, 2002).

A produção, no quotidiano escolar, desse currículo normativo não se faz, contudo, de modo simples e direto, tendo em conta que os processos de transmissão não podem ser pensados sem os correspondentes processos de receção, que envolvem diferentes mecanismos de reinterpretação dos conteúdos a transmitir e inculcar. A resposta dos alunos consiste frequentemente em criar continuidades entre as fronteiras impostas, entre fora e dentro, interior e exterior, nomeadamente através da utilização ruidosa e expansiva das entradas e saídas da sala de aula (ROUDIL, 2006). Nesse sentido, os múltiplos mecanismos de fixação do espaço - a sinalética, o fechamento de portas, os dizeres e os corpos dos funcionários - estão em permanente desconstrução por via das interpelações dos alunos, com o corpo exposto enquanto espaço de expressão e contestação. Falamos aqui dos usos sociopolíticos do corpo, isto é, do modo como indivíduos, diferentemente situados e pluralmente articulados, usam o seu corpo para acederem ao espaço físico da escola, simbolicamente investido, e à possibilidade de construir sentido.

Os seres humanos vivem em complexos e estruturados sistemas de ação corporal e desenvolvem formas de conhecimento incorporado que envolvem, ao mesmo tempo, convenções culturais e performatividade criativa (FARNELL, 1999), sendo que os corpos, em interação e em movimento, funcionam como elementos fundamentais na construção e transmissão de diferentes narrativas individuais e coletivas (MALUF, 2001).

Ao longo da minha experiência de campo, fui podendo participar dessas narrativas, à medida que o meu corpo ia sendo interpelado por diferentes dinâmicas corporais e espaciais. Os sons e a mobilidade, a diferentes velocidades, dos alunos, durante o recreio, e a quietude contrastante dos períodos em que as aulas estão em funcionamento transportaram-me para um mundo de contrastes e inversões sensoriais, que apelavam à minha constante capacidade de adaptação. Quanto à regulação espacial desenvolvida pelos funcionários das escolas, também o meu corpo pôde incorporar a força física e simbólica desses processos em diferentes ocasiões, quando acompanhava os alunos nos seus mapeamentos alternativos e me deparava com as gestualidades e os dizeres que confirmavam as diferentes interdições. Essas experiências sensoriais 
integram, em larga medida, as diferentes maneiras como vamos sendo socializados no espaço e a partir do espaço (FRIAS, 2001).

O modo como o meu corpo foi sendo experimentado durante a pesquisa funcionou, então, como instrumento fundamental de recolha e análise, tornando incontornável a dimensão sensitiva do processo de recolha (ALMEIDA, 1996) e o caráter performativo da pesquisa etnográfica (HASTRUP, 1995). Os meus próprios mapeamentos funcionaram como trajetórias de observação, incorporação e produção do espaço escolar, num duplo processo de acomodação e questionamento. Tal como os outros sujeitos do estudo, também eu tive de (re)aprender novos modos, normalizados e expressivos, de usar o corpo, num terreno, ao mesmo tempo, familiar e estranho.

O pesquisador viajante abraça, desse modo, um paradigma que integra a presença incontornável dos corpos da pesquisa e dos sentidos percorridos durante o trabalho de campo - sinto, logo penso -, e que permite escapar a noções de poder e agência demasiado distanciadas da experiência concreta dos sujeitos e, por consequência, das organizações (PAIS, 2002, p. 55).

As escolas por nós habitadas, objetos de dimensão local, nacional e global, constituem configurações históricas que se inscrevem nos corpos dos sujeitos e nas interações entre esses diferentes corpos. As narrativas corporais participam, desse modo, da construção de um currículo normativo que importa desvendar e que envolve simultaneamente experiências de interiorização das normas e de sujeição voluntária, mas também de desconforto e, não raras vezes, contestação.

Essa consciência de um corpo que se move entre fronteiras físicas simbolicamente investidas surge na continuidade de um poder disciplinar que ocupa os corpos dos indivíduos e produz saber sobre os mesmos; corpos que se sujeitam a múltiplos interditos, integrando-os através de modos de utilização contidos e devidamente codificados; corpos que reivindicam e experimentam o desejo e a vontade de evasão e recriação (FOUCAULT, 1992).

\section{ORGANIZAÇÃO SOCIOESPACIAL E PRODUÇÃO CULTURAL}

A tendência para territorializar o espaço dentro das escolas, fixando e disciplinando a sua utilização, a partir de uma cuidada gestão da circulação dos alunos, ${ }^{11}$ resultou transversal às diferentes escolas etnografadas, apontando para um específico padrão de organização socioespacial, assente numa complexa e dinâmica equação entre proximidade e separação. Um processo contínuo e circular, ao mesmo tempo rotineiro e extraordinário.

A experiência escolar, enquanto produto histórico, está estreitamente associada a um continuado e intenso trabalho de controlo do 
espaço e do tempo, próprio de uma cultura escolar que se foi desenvolvendo e, de certa forma, estabilizando, ao longo de épocas sucessivas. As modalidades de organização e uso do espaço e tempo escolares têm funcionado como importantes vetores de socialização de gerações sucessivas de educadores e educandos (BENITO, 2000; FRAGO, 1998). Contudo, mesmos os alunos, cuja mobilidade condicionada tem funcionado como um poderoso mecanismo de estratificação, surgem como incondicionais produtores de um tempo e espaços escolares que estão para além da "quadrícula fragmentária e limitante” (RECIO, 2007).

Foucault ajuda-nos a refletir sobre o papel da arquitetura na produção das hierarquias sociais e das diferenciações funcionais, assinalando e, ao mesmo tempo, relativizando o efeito organizador e disciplinar dos edifícios: embora a arquitetura introduza algumas configurações específicas no campo das relações sociais, permitindo uma certa distribuição e codificação das relações interpessoais e dos sujeitos que as produzem, a imaginação e prática humanas acabam por complexificar sempre o plano arquitetónico (FOUCAULT, 1994b), quer no aproveitamento e ressignificação dos elementos mais rígidos quer na diversificação e flexibilização das modalidades de apropriação.

A aparente constância e solidez dos edifícios constitui uma ilusão que obscurece a permanente negociação entre estrutura, materiais e modos de utilização (KIRBY, 2009). Apesar dos mecanismos de controlo presentes nas organizações, o movimento e a mudança constituem aspetos fundamentais na criação, estruturação, manutenção e alteração das relações sociais e das instituições. Estes dois elementos apontam para o que a vida coletiva tem de improvisante, de desafio às fronteiras espaciotemporais destinadas a restringir os fluxos potencialmente dissidentes e contrastantes.

Em particular nos contextos escolares, é possível olhar para paredes, corredores ou portas como recursos disponíveis para a inscrição de vontades divergentes (BURKE, 2005), de contenção e de expansão, num espaço que se constrói em processos continuados de interação e produção de sentido (FARNELL, 1999).

A relação entre o edifício escolar e as pessoas é, então, essencialmente dialética. Apesar dos seus elementos permanentes, o espaço edificado funciona como um molde, e não apenas como cenário, a partir do qual, e no qual, os diferentes sujeitos imprimem as suas dinâmicas. O uso pedagógico e disciplinar que os agentes escolares fazem do seu espaço, bem como as diferentes práticas de apropriação desenvolvidas pelos alunos, mostram como a ação humana impõe ao espaço edificado uma permanente plasticidade.

Esse processo só parcialmente se inscreve na arquitetura escolar. Os corpos dos habitantes da escola, na sua materialidade em movimento e em interação, funcionam como a matéria-prima desses desenhos 
transitórios, surpreendíveis a partir de uma observação etnográfica continuada, que explora diferentes modos de interpretar o espaço como lugar praticado (CERTEAU, 1998). Enquanto conjunto de relações sociais continuamente instituídas e simbolizadas, o espaço constitui um domínio fundamental do devir histórico, permitindo pensar o político também a partir dos elementos quotidianos e acidentais.

Tendo em conta uma definição ontológica do espaço (JIMÉNEZ, 2003), foi possível experimentar e pensar as interações sociais e os corpos em movimento como elementos estruturantes na construção da escola enquanto campo sociopolítico, envolvendo possibilidades, escolhas e uma inscrição específica das modalidades reprodutoras, resistentes e transformadoras.

As diferentes práticas associadas à vigilância e disciplinação dos comportamentos discentes permitem a reapropriação criativa da organização por diferentes indivíduos e grupos, apontando para múltiplas maneiras de fazer a escola. A regulação do espaço escolar integra, desse modo, todo um conjunto de experimentações, convergentes e divergentes, que relativizam os processos de estreitamento e fechamento, obrigando à sua permanente (re)invenção.

Associada a um limite, há sempre uma fronteira, que envolve uma “contradição dinâmica entre cada delimitação e sua mobilidade" (CERTEAU, 1998, p. 212). As fronteiras espaciais presentes nas organizações escolares prestam-se a diferentes modos de apropriação, abrindo para um conjunto vasto de questões em torno do lugar da escola como espaço de interligação de diferentes segmentos da sociedade, no qual se inscrevem e atualizam expectativas individuais, grupais e institucionais diversas.

Refletir em torno da capacidade de agir dos seres humanos implica tomar os habitantes da Escola como agentes ativos, não apenas na transformação das disposições culturais, mas também na sua reprodução. As administrações escolares e os profissionais da escola (re)inventam-se a partir do modo como definem a distribuição e apropriação dos espaços e tempos escolares, através de diferentes instrumentos de regulação e de distintas modalidades de intervenção, com vista a controlar o modo como os alunos vivem a escola. Por sua vez, os alunos criam desenhos próprios, ao mesmo tempo, inovadores e previsíveis, quando transgridem e reproduzem as normas espaciais que lhes são impostas.

É importante ter em atenção as múltiplas faces do que se ensina e aprende nas escolas, e que atravessa diferentes contextos de vida, projetando-se, ainda, num futuro permanentemente atualizado. Corpo e espaço constituem, desse modo, locus, objeto e matéria-prima de uma complexa rede de vigilância (RATTO, 2007) destinada à conservação de uma específica ordem - escolocêntrica (LOPES, 2010) -, assente na adequação das atitudes e comportamentos dos alunos ao trabalho e normatividade escolares. 
À semelhança do que Aquino (2011) refere relativamente ao contexto brasileiro, a resposta dos funcionários da escola à gestão das mobilidades discentes revela a existência de todo um dispositivo pedagógico assente numa visão extensiva e amplificadora do que se pode entender por comportamentos dissonantes.

Apesar disso, o que a experiência etnográfica permitiu perceber é que os alunos contrariam, de um modo sistemático, as restrições espaciais e corporais que lhes são impostas, sendo que, a esse nível, o espectro de discentes envolvidos estende-se muito para além daqueles que são classificados como indisciplinados, alguns dos quais objeto de processos disciplinares. Essa espécie de efervescência que habita as escolas numa "fusão provisória e conflitual” (GUIMARÃES, 2010, p. 420) parece conduzirnos para lá de uma leitura exclusivamente assente na ideia de resistência, sem contudo a negar, na medida em que esta "poder ser, ela própria, um artefacto teórico que mascara o simples desejo de existência” (PAIS, 2008, p. 12). Desejo que expande e (re)desenha os espaços e os tempos prescritos, e mostra como as regras criadas pelos adultos não conseguem afirmar-se como os únicos referenciais, ou os referenciais mais valorizados, no modo como a vida é experimentável e experimentada pelas gerações mais jovens.

A escola não funciona, desse modo, como uma tradução sólida e inabalável de um poder cultural dominante, mas, antes, como um campo constituído por conflitos entre diferentes referenciais. As relações pedagógicas que se estabelecem entre educadores e educandos, expostas a pressões por maior conformidade, são contextos fundamentais para a compreensão desses desafios simbólicos (MELUCCI, 1997).

Uma visão plástica do quotidiano escolar permite ultrapassar uma eventual abordagem homogeneizadora dos comportamentos, bem como assumir a dimensão idiossincrática dos diferentes, e conflituantes, modos de habitar a escola (AQUINO, 2011, p. 463). A dimensão performativa das relações socioespaciais, envolvendo múltiplos atores, cenários e guiões, permite perceber que existe uma competição que se alimenta de um movimento circular e mutuamente constitutivo de obrigações/ proibições e resistências/contestações.

Ao longo dos prolongados processos de socialização escolar, na procura continuada do seu espaço de afirmação institucional, educadores e alunos vão experimentando novos modos de afirmarem as suas vontades e posições e, num certo sentido, naturalizando esses encontros disciplinares, que funcionam como momentos em que os diferentes protagonistas se definem e problematizam mutuamente. O continuado confronto entre as práticas quotidianas e o desejo de tornar a escola um lugar habitável pode, contudo, levar a evidentes processos de perda de sentido, associados à experimentação de uma autoridade permanentemente contestada, por parte dos educadores, e a um fortemente condicionado campo de participação vivenciado pelos alunos. 
A ação pedagógica, assente em valores e princípios morais que suportam as funções e finalidades históricas da escola, e os processos dinâmicos de receção que lhes estão estreitamente associados merecem um olhar atento por parte dos investigadores sociais, com vista a compreender os processos pelos quais a Escola se atualiza quotidianamente como guardiã e veículo transmissor de uma certa herança cultural, num território cujas fronteiras porosas exigem o permanente confronto entre diferentes modos de produzir o espaço, o tempo e o corpo enquanto dimensões vitais do viver individual, grupal e coletivo.

\section{REFERÊNCIAS}

ABÉLÈS, Marc. Pour une anthropologie des institutions. L'Homme, n. 135, p. 65-85, jul./set. 1995.

ABRANTES, Pedro. Os muros da escola: as distâncias e as transições entre ciclos de ensino. 2008. Tese (Doutorado) - Instituto Universitário de Lisboa, Lisboa, 2008.

ALMEIDA, Miguel Vale de. Corpo presente. Antropologia do corpo e da incorporação. In: ALMEIDA, Miguel Vale de Almeida. Corpo presente: treze reflexões antropológicas sobre o corpo. 1. ed. Oeiras: Celta, 1996. cap. 1, p. 1-22.

AQUINO, Julio Groppa. Da (contra) normatividade do cotidiano escolar: problematizando discursos sobre indisciplina discente. Cadernos de Pesquisa, São Paulo, v. 37, n. 131, p. 481-510, maio/ago. 2011. Disponível em: <http://www.scielo.br/pdf/cp/v41n143/a07v41n143.pd>. Acesso em: jan. 2016.

BENITO, Agustín Escolano. Tiempos y espacios para la escuela. Madrid: Biblioteca Nueva, 2000.

BURKE, Catherine. Containing the school child: architectures and pedagogies. Paedagogica Historica, v. 41, n. 4-5, p. 489-494, 2005. Disponível em: <http://www.tandfonline.com/doi/ abs/10.1080/00309230500165635\#.UlUHuNKsiSo>. Acesso em: jan. 2012.

CERTEAU, Michel de. A invenção do cotidiano. Petrópolis: Vozes, 1998.

CRESPO, Jorge. A história do corpo. Lisboa: Difel, 1990.

DELALANDE, Julie. La cour de l'école: un lieu commun remarquable. Recherches familiales, n. 2, p. 25-36, 1/2005. Disponível em: <http://www.cairn.info/revue-recherches-familiales-2005-1. htm>. Acesso em: abr. 2012.

FARNELL, Brenda. Moving bodies, acting selves. Annual Review of Anthropology, v. 28, p. 341-373, 1999. Disponível em: <http://www.annualreviews.org/toc/anthro/28/1>. Acesso em: abr. 2012.

FOUCAULT, Michel. Microfísica do poder. Rio de Janeiro: Graal, 1992.

FOUCAULT, Michel. Les mailles du pouvoir. In: DEFERT, Daniel; EWALD, François. Dits et écrits: vol. IV, 1980-1988, texte 297. Paris: Gallimard, 1994a.

FOUCAULT, Michel. Espace, savoir et pouvoir. In: DEFERT, Daniel; EWALD, François. Dits et écrits, vol. IV, 1980-1988, texte 310. Paris: Gallimard, 1994b.

FRAGO, António Viñao. L'espace et le temps scolaires comme objet d'histoire. Histoire de l'éducation, n. 78, p. 89-108, 1998. Disponível em: <http://ife.ens-lyon.fr/edition-electronique/ archives/histoireeducation/web/fascicule.php?num_fas=196>. Acesso em: abr. 2013.

FRIAS, Aníbal. Une introduction à la ville sensible. Recherches en anthropologie au Portugal: revue annuelle du Groupe Anthropologie du Portugal, n. 7, p. 11-36, 2001.

GALLO, Luz Elena; MARTINEZ, Leidy Johana. Líneas pedagógicas para una educación corporal. Cadernos de Pesquisa, v. 45, n. 157, p. 612-629, jul./set. 2015. Disponível em: <http://www.scielo. br/pdf/cp/v45n157/1980-5314-cp-45-157-00612.pdf>. Acesso em: jan. 2016. 
GUIMARÃES, Áurea M. Novos regimes de ver, ouvir e sentir afetam a vida escolar. Educação, Santa Maria, v. 35, n. 3, p. 413-430, set./dez. 2010. Disponível em: <http://cascavel.ufsm.br/ revistas/ojs- 2.2.2/index.php/reveducacao/article/view/2352>. Acesso em: mar. 2012.

HASTRUP, Kirsten. A passage to anthropology. Between experience and theory. Londres: Routledge, 1995.

JIMÉNEZ, Alberto Corsín. On space as a capacity. Journal of the Royal Anthropological Institute, v. 9, p. 137-153, 2003. Disponível em: <http://digital.csic.es/bitstream/10261/85028/1/On\%20 space\%20as\%20a\%20capacity.pdf.>. Acesso em: jan. 2016.

JULIA, Dominique. A cultura escolar como objeto histórico. Revista Brasileira de História da Educação, Maringá, n. 1, p. 9-43, jan./jun, 2001. Disponível em: <http://www.scielo.br/scielo. php?script=sci_arttext\&pid=\$1517-97022004000100008\&Ing=en \& nrm=iso $>$. Acesso em: abr. 2013.

KIRBY, Peter Wynn. Lost in "space": an anthropological approach to movement. In: KIRBY, Peter Wynn. Boundless worlds. An anthropological approach to movement. 1. ed. New York: Berghahn Books, 2009. cap. 1, p. 1-28.

LEANDRO, Alexandra. Limites, desordens e mediações: uma etnografia em espaço escolar. 2013. Tese (Doutorado) - Instituto Universitário de Lisboa, Lisboa, 2013. Disponível em: <http://hdl. handle.net/10071/7431>. Acesso em: jan. 2016.

LOPES, João Teixeira. Do politeísmo cultural contemporâneo ao trabalho escolar de eliminação da dissonância. Sociologia: Revista do Departamento de Sociologia da FLUP, Porto, v. 20, p. 281-290, 2010. Disponível em: <http:// http://ler.letras.up.pt/uploads/ficheiros/8800.pdf>. Acesso em: jan. 2016.

MALUF, Sônia Weidner. Corpo e corporalidade nas culturas contemporâneas: abordagens antropológicas. Esboços, v. 9, n. 9, p. 87-101, 2001. Disponível em: <https://periodicos.ufsc.br/ index.php/esbocos/article/view/563>. Acesso em: fev. 2012.

MAUSS, Marcel. Sociologie et anthropologie. Paris: PUF, 1983.

MELUCCI, Alberto. Juventude, tempo e movimentos sociais. Revista Brasileira de Educação, n. 5-6, p. 6-14, maio/dez. 1997. Disponível em: <http://educa.fcc.org.br/scielo.php?script=sci arttext\&pid=S1413- 24781997000200002\&lng =pt\&nrm=iso $>$. Acesso em: abr. 2012.

NÓBREGA, Terezinha Petrucia da. Qual o lugar do corpo na educação? Notas sobre conhecimento, processos cognitivos e currículo. Educação \& Sociedade, Campinas, v. 26, n. 91, p. 599-615, maio/ago. 2005. Disponível em: <http://www.cedes.unicamp.br> Acesso em: jan. 2016.

NUGENT, David. Governing States. In: NUGENT, David; VINCENT, Joan. A companion to the anthropology of politics. Oxford: Blackwell, 2004. cap. 13, p. 198-215.

PAIS, José Machado. Sociologia da vida quotidiana. Lisboa: Imprensa de Ciências Sociais, 2002.

PAIS, José Machado. Máscaras, jovens e “escolas do diabo”. Revista Brasileira de Educação, Rio de Janeiro, v. 13, n. 37, p. 7-21, jan./abr. 2008. Disponível em: <http://www.scielo.br/scielo. php?script=sci_arttext\&pid=\$1413-24782008000100002\&lng=en\&nrm=iso $>$. Acesso em: abr. 2012.

PERRENOUD, Philippe. Ofício de aluno e sentido do trabalho escolar. Porto: Porto, 2002.

RATTO, Ana Lúcia Silva. Disciplina, vigilância e pedagogia. Cadernos de Pesquisa, São Paulo, v. 37, n. 131, p. 481-510, maio/ago. 2007. Disponível em: < www.scielo.br/pdf/cp/v37n131/a1237131.pdf>. Acesso em: jan. 2016.

RECIO, Rosa Vasquez. Reflexiones sobre el tiempo escolar. Revista Iberoamericana de Educación, Madrid, v. 42, n. 6, p. 1-11, maio 2007. Disponível em: <http://www.rieoei.org/1733.htm>. Acesso em: jan. 2012.

RESENDE, José Manuel. A sociedade contra a escola? A socialização política escolar num contexto de incerteza. Lisboa: Instituto Piaget, 2008. 
ROUDIL, Nadine. Ordre et désordre au collège. Intégration adolescente et normes scolaires. International Journal on Violence and Schools, n. 2, p. 50-72, dez. 2006. Disponível em: <http://www.ijvs.org/3- 6224-Article.php?id=27\&tarticle=0>. Acesso em: dez. 2008.

STRAZZACAPPA, Márcia. A educação e a fábrica de corpos: a dança na escola. Cadernos CEDES, Campinas, v. 21, n. 53, p. 69-83, 2001. Disponível em: <http://www.scielo.br/pdf/ccedes/v21n53/ a05v2153.pdf >. Acesso em: jan. 2016.

ALEXANDRA LEANDRO

Professora do Centro de Estudos das Migrações e das Relações Interculturais - CEMRI - da Universidade Aberta - UAb -, Lisboa, Portugal

mleandro@cemri.uab.pt 